\title{
RECURSOS DIDÁTICOS PARA O ENSINO DE BOTÂNICA: UMA AVALIAÇÃO DAS PRODUÇÕES DE ESTUDANTES EM UNIVERSIDADE SERGIPANA
}

\author{
G. M. A. MATOS ${ }^{1 *}$, M. MAKNAMARA ${ }^{2}$, E. C. A. MATOS $^{1}$ e A. P. PRATA ${ }^{1}$ \\ ${ }^{1}$ Universidade Federal de Sergipe - UFS \\ ${ }^{2}$ Universidade Federal do Rio Grande do Norte - UFRN \\ gilda.amarante@globo.com*
}

Artigo submetido em outubro/2013 e aceito em junho/2015

DOI: 10.15628/holos.2015.1724

\section{RESUMO}

Os recursos didáticos são considerados elementos importantes no trabalho dos conteúdos de Botânica. Este trabalho objetivou testar e avaliar os diferentes recursos didáticos e atividades práticas elaboradas pelos licenciandos do Curso de Ciências Biológicas da Universidade Federal de Sergipe que enfatizaram o Ensino de Botânica em suas monografias. Os recursos foram aplicados em uma escola pública aracajuana e avaliados por meio de questionário e ficha própria. O caráter diferente e criativo destas aulas facilitou a assimilação e compreensão dos conceitos propostos e contribuiu para o reforço, ilustração e construção do conhecimento do aluno de maneira mais dinâmica e significativa. Conclui-se que os recursos aplicados e avaliados contribuíram para a aprendizagem significativa, pois o contato com os materiais expostos durante as atividades possibilitou aos alunos perceberem as plantas no cotidiano, sua importância e diversidade.

PALAVRAS-CHAVE: Ensino de Botânica, aulas práticas, avaliação de recursos didáticos.

\section{EDUCATIONAL RESOURCES FOR TEACHING OF BOTANY: AN EVALUATION OF PRODUCTION OF STUDENTS IN UNIVERSITY OF SERGIPE}

\begin{abstract}
The teaching resources are considered important elements in the work of Botany content. This study aimed to test and evaluate the various teaching resources and practical activities designed by undergraduate Course of Biological Sciences of the Federal University of Sergipe that emphasized the teaching of Botany in their monographs. The funds were invested in a public school Aracaju and assessed by questionnaire and record itself. The character of these different and creative classes
\end{abstract}

facilitated the assimilation and understanding of the concepts proposed and contributed to the enhancement, illustration and construction of the student's knowledge in a more dynamic and meaningful. We conclude that the resources applied and evaluated contributed to meaningful learning, as contact with the materials exposed during activities allowed the students realize the plants in everyday life, its importance and diversity.

KEYWORDS: Teaching Botany classes, pratical classes, evaluation of teaching resources. 


\section{INTRODUÇÃO}

Nossa experiência em Sergipe mostra que geralmente os professores evitam as aulas de Botânica, deixando estes conteúdos para o final do ano letivo. Além da insegurança de trabalhar com estes conteúdos, uma das dificuldades enfrentadas pelos professores ao ensinar Botânica é preparar as aulas práticas de forma a aproximar o conteúdo à realidade do aluno. Será então difícil elaborar atividades práticas de Botânica?

Diante destas dificuldades, recursos didáticos são elaborados como resultados de projetos de pesquisa e de monografias em cursos de licenciatura em Ciências Biológicas. No entanto, tais recursos não costumam chegar às salas de aulas, devido a barreiras na interação universidadeescola. Somado a isso, as propostas elaboradas nas universidades muitas vezes não consideram as peculiaridades da sala de aula. Dentre elas, destacamos falta de adequação dos conteúdos a diferentes níveis de ensino, dificuldade de acesso aos recursos para as práticas, e tempo insuficiente para o preparo da atividade pelo professor.

Tendo em vista as necessidades supracitadas, diversos estudos têm procurado colaborar com o desenvolvimento das aulas práticas nas escolas, ao possibilitar a difusão de materiais e possíveis ajustes em aulas a eles correlatas. Nesse sentido, nos indagamos: em que medida os recursos didáticos referentes ao ensino de Botânica podem efetivamente contribuir para o ensino? Neste trabalho, por conseguinte, objetivamos testar, avaliar, divulgar e apontar possíveis adequações ou inadequações aos diferentes recursos didáticos e atividades práticas elaboradas por licenciandos em Ciências Biológicas de uma universidade sergipana que enfatizaram o ensino de Botânica em suas monografias.

\section{ENSINO E APRENDIZAGEM DE BOTÂNICA EM ATIVIDADES PRÁTICAS DE CIÊNCIAS}

A atividade de ensinar não se limita apenas ao professor como elemento ativo que fala e interpreta os conteúdos, sem a preocupação de torna-los significativos para os alunos (ANDRADE et al. 2009). Para este autor, o ensino é um conjunto de atividades praticadas pelo professor visando alcançar um determinado objetivo, tendo como ponto de partida as experiências e conhecimentos prévios dos discentes. Para o aluno conseguir elaborar um novo conhecimento é preciso seu envolvimento, esforço e tempo necessitando ajuda e estimulo não só do professor, assim como dos colegas para superar os obstáculos e conseguir aprender de forma mais significativa (ZABALA, 1998).

Um dos objetivos no ensino de Ciências para o ensino fundamental é desenvolver nos alunos a capacidade de utilizar diferentes fontes de informação e recursos, que valorizem o trabalhar em grupo, tornando-os capazes de ações críticas e cooperativas para a construção do conhecimento (BRASIL, 1998). Os Parâmetros Curriculares Nacionais (PCNs) apresentam uma abordagem construtivista ao sugerir que o ensino de Ciências Naturais precisa ser realizado de modo a favorecer a aprendizagem significativa, à medida que os alunos consigam estabelecer relações entre os conhecimentos prévios e os novos conceitos aprendidos. Neste documento, enfatiza-se que a participação e envolvimento de cada um devem ser delimitados de acordo com as possibilidades dos alunos e da complexidade das situações, podendo assim atender aos objetivos do processo de ensino-aprendizagem. Para que essas possibilidades de participação se 
desenvolvam, torna-se necessária uma intervenção planejada dos professores, de forma progressiva, promovendo o desenvolvimento e autonomia dos alunos (BRASIL, 1997).

A importância das aulas práticas no ensino de Ciências é ressaltada por diversos autores (BARRATT, 2004; KRASILCHIK, 2004; ANDRADE; MASSABNI, 2011; SILVA; MORAIS; CUNHA, 2011). Elas se tornam modalidades didáticas alternativas à aula expositiva e ao livro didático, considerando que este recurso ainda é o principal instrumento de trabalho dos professores (DELIZOICOV; ANGOTTI; PERNAMBUCO, 2002; SILVA; SOUZA; DUARTE, 2009). Atualmente, o ensino de Ciências segue diferentes tendências, e dentre essas, Santos, Chow e Furlan (2008) destacam três que consideram importantes: o ensino a partir da historia das ciências, do cotidiano e da experimentação (práticas). Esta última vertente é de fundamental importância no âmbito do ensino de Ciências, pois em alguns conteúdos a teoria desvinculada da prática pode perder o sentido da construção científica, reforçando que o conhecimento científico se faz a partir da relação lógica entre prática e teoria.

Dessa forma, as atividades práticas para o ensino de Ciências, especialmente nos primeiros contatos com a Ciência, são fundamentais para a construção de uma visão geral do mundo natural, uma vez que possibilitam um maior leque de questionamentos a partir dos conhecimentos prévios sobre os fenômenos (ANDRADE; MASSABNI, 2011). As observações do aluno nas aulas teóricas proporciona a ele desenvolver significados próprios durante as aulas práticas, desenvolvendo o senso crítico e criativo (KRASILCHIK, 2004). As práticas contribuem em vários aspectos na formação dos alunos: proporcionam uma visão mais integrada dos fenômenos e um maior envolvimento emocional com o tema, promovendo a aprendizagem (CAVASSAN; SENICIATO, 2007). Estas aulas ainda permitem aos alunos terem contato direto com os fenômenos, manipulando os materiais e equipamentos e observando organismos, em geral envolvendo a experimentação, contribuindo assim, para o ensino de assuntos mais complexos e pouco palpáveis aos alunos (KRASILCHIK, 2004).

No entanto, Andrade e Massabni (2011) consideram que a aplicação ou não das atividades práticas é uma decisão exclusiva do professor, dado que o mesmo deverá buscar os meios de elaborá-las e desenvolvê-las independentemente dos obstáculos que venham ocorrer. Contudo, Bizzo (2009) ressalta que seja qual for o tipo de aula aplicada, o professor não pode deixar de despertar no aluno a importância da ciência no seu cotidiano, proporcionar a oportunidade de reflexão e ação diante do problema e descobrir diferentes maneiras de entender o mundo. Além de serem importantes por complementar as possíveis lacunas que as aulas teóricas podem deixar (ANDRADE; MASSABNI, 2011), as atividades práticas também são importantes motivadoras no processo de aprendizagem dos alunos (BIZZO, 2009).

Como exemplo de recursos didáticos, podemos citar os jogos didáticos por serem atividades de caráter lúdico, diferente e significativo, apresentando-se como um aliado ao aprendizado. Eles são um recurso alternativo e complementar que pode ser utilizado durante as aulas de ciências e desta maneira tornar a atividade mais atraente e motivadora, atingindo assim diferentes objetivos simultaneamente (LOPES, 2005; FREITAS et al., 2011).

Segundo Oliveira (2007), dentre os conteúdos científicos explorados desde o ensino fundamental ao médio, os de Botânica apresentam diversos problemas e tem sido objeto de estudo de vários pesquisadores. Visando melhorar esta questão, os professores de Ciências buscam novas metodologias que tornem as aulas mais atraentes para os alunos, isto porque, 
geralmente o professor não consegue atingir os objetivos do ensino, enquanto os alunos não conseguem aprender o que é ensinado (NETA et al. 2010).

Esta dificuldade de aprendizagem por parte dos alunos se dá porque a maioria dos alunos sente dificuldade de perceber e saber onde poderão aplicar seus conhecimentos botânicos (BARRATT, 2004). Muitos motivos podem ser apontados para o problema, porém o ponto fundamental parece ser a nossa relação para com as plantas, ou seja, o nosso pouco conhecimento e interesse pelas plantas, conhecida como "Cegueira Botânica". Isto se dá porque as pessoas, geralmente, tendem a ser mais interessadas em animais do que em plantas e não percebem o quanto as plantas são importantes para nossa sobrevivência, para o ecossistema e, até em casos mais extremos, não percebem que as plantas são seres vivos (WANDERSEE; SCHUSSLER, 2001; OLIVEIRA, 2007). Esta falta de percepção dificulta o processo de ensino-aprendizagem dos conteúdos de Botânica, tornando esta "Cegueira Botânica" mais evidente (OLIVEIRA, 2007).

Uma das medidas a serem tomadas para mudar esta situação, é conscientizar os professores de que o ensino de Botânica não precisa se ater apenas às informações contidas nos livros didáticos e nos meios de comunicação, e sim necessita mais de aulas práticas, especialmente em campo, para que o aluno perceba e resgate a relação homem-natureza (FIGUEIREDO, 2009). Corroborando com essa ideia, Cavassan e Seniciato (2007) afirmam que as aulas de campo apresentam-se como um grande laboratório natural onde a biodiversidade é extraordinariamente superior a qualquer outro ambiente reproduzido em sala de aula ou em laboratórios, o que desperta nos alunos valores éticos e os aproxima dos elementos naturais do seu ambiente, não dissociados do meio onde vive.

\section{PROCEDIMENTOS METODOLÓGICOS}

A pesquisa qualitativa é o tipo de abordagem de pesquisa que considera as diversas perspectivas e contextos sociais relacionados à questão pesquisada, e na coleta de dados, a subjetividade e as reflexões do pesquisador e dos pesquisados são parte da pesquisa (FLICK, 2009). A abordagem metodológica adotada neste trabalho é a qualitativa em virtude do caráter avaliativo do estudo. Os questionários foram adotados para viabilizar coleta de dados mais precisos, como também dá liberdade aos respondentes, possibilitando uma menor distorção dos dados (MARCONI; LAKATOS, 2010).

O estudo foi desenvolvido com as monografias elaboradas pelos licenciandos do Curso de Ciências Biológicas da Universidade Federal de Sergipe (UFS) que enfatizaram o ensino de Botânica. Foi realizada inicialmente uma catalogação dos trabalhos para conhecimento do universo de dados.

Objetivando viabilizar a realização do estudo e considerando restrições de tempo para execução do trabalho e acessibilidade às salas de aula para aplicação dos recursos, foram estabelecidos critérios de escolha dos trabalhos encontrados. Os recursos didáticos foram escolhidos seguindo os critérios:

I. Trabalhos cujo conteúdo elaborado fosse orientado para o ensino fundamental;

II. Trabalhos que propusessem ao menos uma atividade a ser realizada com os alunos. 
As propostas foram confeccionadas e testadas em uma instituição de ensino fundamental, aplicadas pelos pesquisadores deste trabalho e monitoradas pelo professor da turma. Este estudo foi realizado com 25 alunos, com idade de 11 a 15 anos do 70 ano de uma Escola Municipal de Ensino Fundamental, situada no município de Aracaju, estado de Sergipe.

Para realização do estudo, solicitamos a permissão da direção da escola, através da assinatura do termo de consentimento de pesquisa, assim como pelos pais dos alunos e pelo professor. A avaliação dos recursos didáticos foi composta da avaliação dos alunos e do professor por meio de questionários e a avaliação dos pesquisadores por meio de ficha própria. Os questionários utilizados como instrumento de avaliação dos alunos e o do professor foram elaborados pelos pesquisadores, enquanto que o instrumento de avaliação dos pesquisadores foi elaborado a partir de adaptações dos parâmetros avaliativos elaborados por Vasconcelos e Souto (2003).

As respostas obtidas nos questionários dos alunos foram analisadas e distribuídas em categorias com o objetivo de melhor apresentar e discutir os resultados obtidos, criadas a partir dos aspectos apontados pelos alunos para cada atividade. Ao todo, foram criadas quatro categorias: caráter diferente e lúdico da aula; satisfação em trabalhar em grupo; oportunidade de aprofundar os conteúdos de botânica; nível de dificuldade do jogo.

\section{RESULTADOS E DISCUSSÕES}

Ao analisar as monografias elaboradas pelos licenciandos do Curso de Ciências Biológicas da Universidade Federal de Sergipe (UFS), foram encontradas nove trabalhos que enfatizaram o ensino de Botânica, que estão abaixo relacionados:

1. Maria Laura Vieira Santana/Maria Overlandia Oliveira - 2006. Inserindo as Plantas Medicinais no Ensino de Ciências da 6ạ Série do Ensino Fundamental. Cartilha (Plantas Medicinais e suas utilidades).

2. Marize de Jesus Santiago - 2007. Bromeliáceas do Parque Nacional Serra de Itabaiana Descrição Botânica e Importância Ecológica. Paradidático.

3. Adeline Brito Sales - 2008. A Flora Nativa no Ensino De Biologia em Escolas de Aracaju: Situação Atual e contribuição para a contextualização do tema. Atlas (Flora Sergipana).

4. Anderson de Carvalho Silva - 2008. Utilização de recurso Paradidático de Botânica no Ensino Fundamental. (Manual de Práticas de Botânica).

5. José Elvino do Nascimento Júnior - 2009. Divulgação Científica Sobre as Plantas do Parque Nacional Serra de Itabaiana, Sergipe. Livro.

6. Elaine Cristine do Amarante Matos - 2009. Disciplina Botânica Sistemática: Proposta de atividade de Campo. Manual de aula de campo.

7. Daniel Silva Melo - 2011. Bromélias da Mata Atlântica de Sergipe Como Ferramenta para Aulas Práticas de Botânica. Livro.

8. Christopher Anderson Santos Souza - 2011. Utilização de Frutos da Vegetação de Sergipe Como Recurso Didático Para o ensino de Ciências e Biologia. Guia. (Construção de uma Mini Carpoteca). 
9. Giselle Gomes Conceição - 2011. Cactaceae em Sergipe, Brasil: uma abordagem didática de suas características para o ensino fundamental, médio e superior. Pôsteres.

Dentre os trabalhos encontrados, com o objetivo de colaborar com o desenvolvimento do ensino de Ciências e possibilitar ao professor o conhecimento de recursos didáticos, produzidos na academia, que o auxiliem nas aulas práticas de botânica, foram selecionados quatro trabalhos de monografias que se enquadraram nos critérios estabelecidos nos procedimentos metodológicos: Anderson de Carvalho Silva - 2008. Utilização de recurso Paradidático de Botânica no Ensino Fundamental. Manual de Práticas de Botânica; Christopher Anderson Santos Souza - 2011. Utilização de Frutos da Vegetação de Sergipe Como Recurso Didático Para o ensino de Ciências e Biologia. Guia: Construção de uma Mini Carpoteca; Daniel Silva Melo - 2011. Bromélias da Mata Atlântica de Sergipe Como Ferramenta para Aulas Práticas de Botânica. Livro; Marize de Jesus Santiago - 2007. Bromeliáceas do Parque Nacional Serra de Itabaiana Descrição Botânica e Importância Ecológica. Paradidático.

Na primeira etapa da pesquisa entramos em contato com a escola, que nos autorizou o contato com o professor. Este se disponibilizou a dar todo apoio necessário à pesquisa, de modo que ficou acordado que ele ministraria todo o conteúdo teórico de botânica numa turma de sétimo ano, enquanto nós pesquisadores aplicaríamos, simultaneamente, as aulas práticas como forma de reforço do conteúdo estudado.

\subsection{Primeira atividade - Órgãos das plantas e suas funções.}

A primeira atividade prática aplicada foi a dos Órgãos das plantas e suas funções, recurso retirado da monografia de Anderson de Carvalho Silva (2008).

De acordo com a proposta do autor, esta atividade deveria ser aplicada no pátio da escola, onde o professor deveria: fazer a divisão da turma em quatro grupos e determinar as estruturas específicas da planta a qual cada grupo deteria suas atividades. Em seguida os grupos deveriam, em meio às espécies vegetais dispostas no pátio da escola, selecionar aquelas que possuíam tipos variados da estrutura na qual estavam trabalhando. Essas estruturas poderiam ser fotografadas, desenhadas, decalcadas ou até mesmo coletadas com o auxílio do professor. Na etapa seguinte à coleta das informações, os alunos distribuiriam em uma cartolina as estruturas, desenhos ou fotografias extraídos das plantas, identificando-as e definindo-as com suas próprias palavras. Por fim, deveriam pesquisar a definição científica dessas estruturas e dispô-las na mesma cartolina e então em outro momento deveriam apresentar seu trabalho ao resto da turma. Entretanto, esta atividade não pode ser feita seguindo as instruções do autor, devido a dois fatores: primeiro, a escola não tinha área com vegetação em seu pátio; segundo, é que estava sendo realizadas neste horário outras atividades no local. Então, como alternativa, coletamos diferentes tipos de cada órgão de planta e levamos para a escola e no laboratório de ciências realizamos a atividade com os alunos.

No dia de realização desta atividade havia 24 estudantes presentes. No inicio, os alunos estavam desinteressados com a atividade e ficaram conversando muito, o que causou dificuldade em formar os grupos e sortear qual órgão da planta cada grupo iria pesquisar, desenhar e apresentar no final da atividade. 


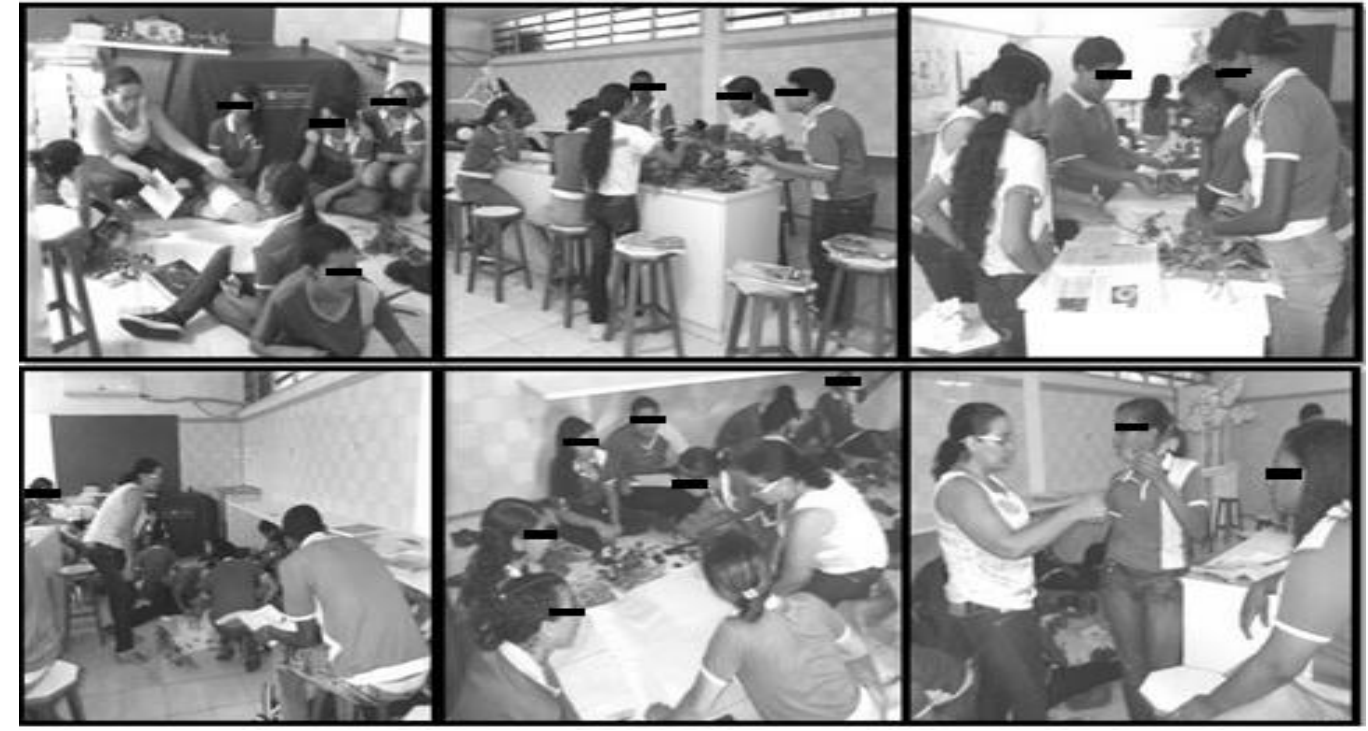

Figura 1- Realização da primeira parte da atividade um. Autor: G.M.A.Matos

No entanto, aos poucos, eles começaram a se interessar pela atividade, separando o órgão da planta ao qual estavam pesquisando. Em seguida alguns grupos se acomodaram no chão, outros nas bancadas do laboratório. Mais calmos, começaram a comentar entre si as funções e características de cada órgão e a se preocuparem com a qualidade dos desenhos. No entanto, explicamos que não precisariam fazer "desenhos perfeitos" como também poderiam escrever em cada figura desenhada, com as próprias palavras, sobre o tipo de órgão e sua função. Observamos que a atividade aos poucos ficou mais prazerosa para maioria dos alunos.

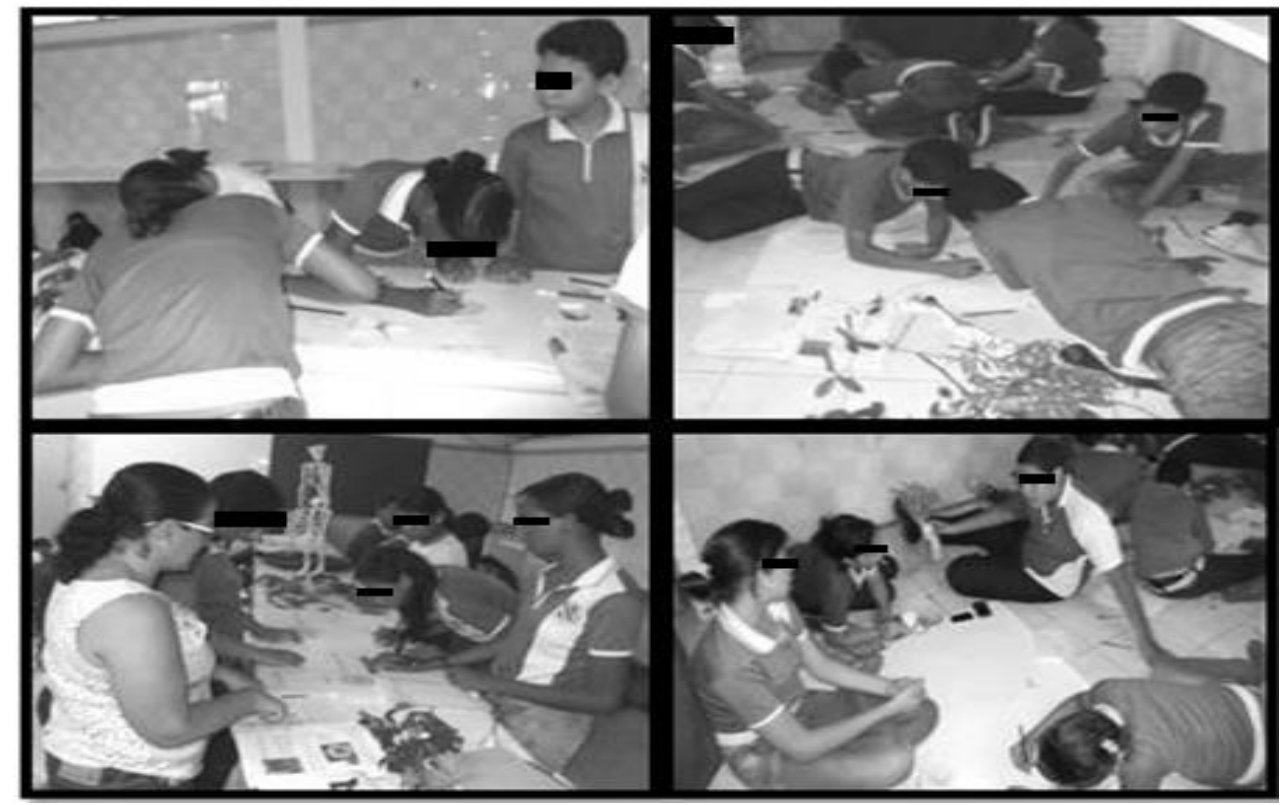

Figura 2 - Momento de desenhar as estruturas botânicas na primeira atividade. Autor: G.M.A.Matos

No final da aula, os alunos apresentaram os trabalhos para os colegas espontaneamente. Porém, chamou a atenção o fato de que eles não tiveram segurança de falar o conteúdo que eles escreveram nos cartazes, preferindo ler o conteúdo dos livros referente ao órgão pesquisado. 


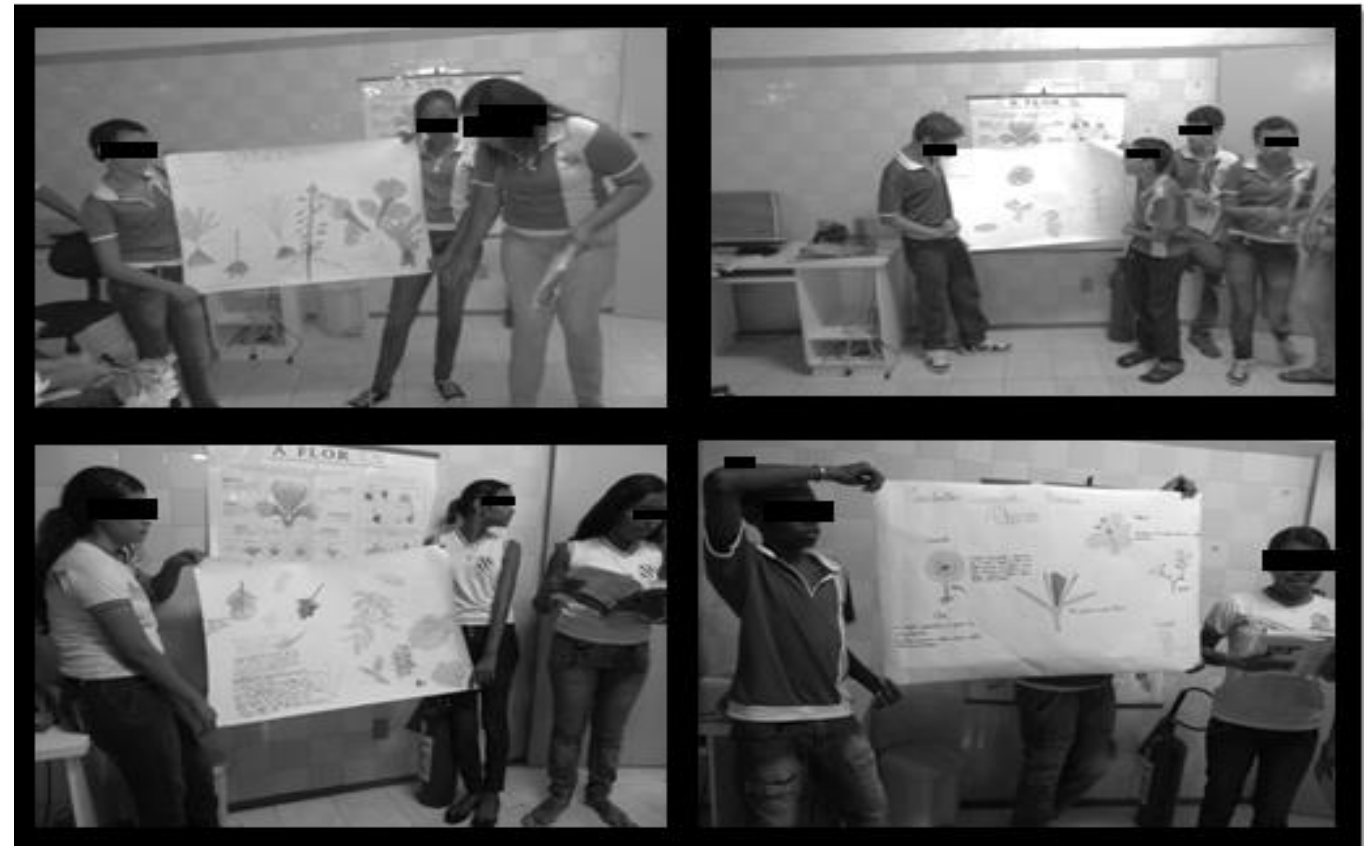

Figura 3 - Apresentação dos trabalhos da primeira atividade pelos alunos. Autor: G.M.A.Matos

Ao refletir sobre este fato, pensamos em duas hipóteses a considerar para essa insegurança: a primeira seria a de que os alunos não tiveram uma aprendizagem significativa, por não terem conseguido explicitar seus conhecimentos sobre o conteúdo visto em sala de aula. Segundo Libâneo (2011), o aluno que aprendeu mecanicamente sente maior dificuldade em relacionar um conceito a outro, não conseguindo elaborar uma relação geral para casos particulares. Sobre os alunos terem recorrido a informações do livro em detrimento de suas anotações em cartazes, Batista (2003) auxilia nosso entendimento ao explicar que o livro didático contém os conteúdos de modo organizado e sequenciado, tornando-se um recurso didático teórico e prático de apoio importante para o aluno.

Nossa segunda hipótese explicativa da insegurança dos alunos considera o fato de que o professor utiliza o livro didático como principal recurso durante as aulas. Com isso, atendo-se a passar o conteúdo de forma acabada, geralmente sem debate, sem questionamentos e não valorizando os conhecimentos prévios dos alunos, o docente passaria a ideia de que o livro didático é uma fonte de conhecimento confiável. Nesse sentido, em muitas escolas, ainda hoje, os livros didáticos continuam sendo a principal fonte de informação para os professores e também para os alunos, sobressaindo a ideia de que eles teriam "a palavra final" sobre os assuntos que abordam (BRASIL, 1998; DELIZOICOV; ANGOTTI; PERNAMBUCO, 2002; NETO; FRACALANZA, 2003; SILVA; SOUZA; DUARTE, 2009).

A realização da atividade foi feita em duas horas aula seguidas, devido ao pouco tempo para execução deste estudo. No entanto, a atividade seria mais proveitosa se tivesse sido desenvolvida de acordo com o autor do recurso, ou seja, em duas etapas, uma em que os alunos observariam e desenhariam os órgãos; e outra em casa, na qual eles pesquisariam sobre o órgão, e posteriormente apresentariam para a turma em outra aula.

Os alunos avaliaram o recurso didático de forma positiva, a maioria ( $75 \%$ dos alunos) o classificaram como muito bom, (20\%) como bom e (5\%) como satisfatório. Diferentes aspectos foram apontados nas justificativas dos alunos nas respostas dos questionários: 
a) O caráter diferente e lúdico da aula

Foi uma aula agradável e diferente das outras (Aluna "S", 13 anos).

Porque é a primeira vez que tenho uma aula assim (Aluna "B", 13 anos).

Porque foi diferente e muito legal (Aluna "F", 14 anos).

Gostei muito, porque eu adorei desenhar as folhas e também foi diferente e muito legal (Aluna "A", 13 anos).

Porque foi uma aula prática muito diferente e legal (Aluna "V", 11 anos).

Porque foi uma aula muito divertida uma aula diferente (Aluna " $M$ ", 13 anos).

b) Satisfação em trabalhar em grupo

Porque teve muito parcerismo no meu grupo (Aluna "L", 12 anos).

Porque é bom fazer pesquisas e interagir com os alunos. Foi demais espero que tenhamos mais pesquisas (Aluna " $R$ ", 12 anos).

Porque eu trabalhei em grupo com meus colegas de sala não ficou aquela coisa chata o professor só falando e a gente praticou um pouco de que o que nós já sabíamos (Aluna "K", 12 anos).

c) Oportunidade de aprofundar os conteúdos de botânica

Porque a gente fica sabendo cada vez mais as funções das plantas (Aluno " $\mathrm{H}$ ", 13 anos).

Porque as pessoas aprendem mais sobre a aula e das plantas, flor, caules e outras mais (Aluna " $D$ ", 12 anos).

Porque eu me diverti e aprendi muito sobre as plantas e as funções (Aluna "E", 12 anos).

Porque nós desenhamos as folhas, falamos sobre elas (...) (Aluna " $\mathrm{N}$ ", 13 anos).

Porque conhecemos plantas diferentes e podemos estudar as plantas (Aluna " $\mathrm{C}$ ", 13 anos).

Porque aprendemos coisas novas (Aluna " $G$ ", 14 anos).

Porque estou aprendendo muita coisa (Aluno "J", 12 anos).

Quando questionados se possuíam alguma crítica e/ou sugestão, dois alunos não responderam, dezoito alunos disseram que não, e alguns dos alunos destacaram o quanto gostaram da aula. No entanto alguns alunos ressaltaram a questão da organização na realização da atividade: 
Dividir em grupos menores. Porque vira bagunça... e mais organização (Aluno "P", 12 anos).

Sim mais organização (Aluna "E", 12 anos).

Organização e mais participação dos alunos (Aluna "C", 13 anos).

A avaliação do professor também foi positiva, conforme a realizada pelos alunos. Ele considerou muito boa a adequação da prática à série de ensino, assim como em relação às informações necessárias para a compreensão do tema em estudo e para a contribuição para a aprendizagem dos alunos. No entanto, em relação ao cumprimento dos objetivos da prática, ele concede o conceito bom. Quanto ao tempo recomendado para a aplicação do recurso e à participação dos alunos ele dá o conceito satisfatório.

A questão do tempo de realização da atividade também foi observada também pelos pesquisadores, ao qual não seguiu as recomendações de dividir a prática em dois momentos, como também foi observada por um dos alunos:

Porque não gostei das atitudes de "Dona" Gilda. Ex: Apressar os grupos e etc. (Aluno "P", 12 anos).

Na avaliação dos pesquisadores, a primeira atividade é adequada à série proposta, apresentando conteúdo atualizado, coerência entre as informações, recursos visuais de boa qualidade, com uma atividade inovadora e criativa, de fácil execução e que atinge aos objetivos propostos. Nela, os alunos trabalharam em grupo, discutiram conceitos e desenvolveram a criatividade junto aos colegas, promovendo assim sua autonomia e a interação entre os colegas, de forma que eles perceberam a importância e o papel que cada um ocupa no grupo. Ressalta-se a importância de seguir as recomendações de tempo e ordem de execução da atividade segundo o autor que elaborou o recurso para um melhor desenvolvimento da atividade.

\subsection{Segunda atividade - Salada de frutas.}

A segunda atividade prática foi a Salada de frutas, recurso retirado do trabalho de monografia de Christopher Anderson Santos Souza (2011).

De acordo com a proposta do autor, para esta atividade ser aplicada o professor deveria dividir a turma em dois grupos. Cada grupo ficaria responsável por levar três ou quatro diferentes frutas para aula. De posse das frutas, os alunos deveriam fazer um corte longitudinal em cada fruto, com o objetivo de ilustrar as partes que compõem um fruto, como também o tipo de fruto. Depois de desenhar os frutos, cada grupo deveria expor os desenhos com as principais características de cada fruto levado para a sala. No final, os alunos produziriam uma salada de frutas e se deleitariam com a salada de frutas produzidas por eles mesmos.

A única restrição feita a essa atividade foi o uso da faca, por ser um objeto cortante o professor não autorizou o manuseio desta pelos alunos. Então fizemos a salada de frutas, ao passo que os alunos faziam as ilustrações.

No dia de realização desta atividade havia 25 estudantes presentes. Nesta atividade os alunos participaram mais ativamente. Inicialmente estavam querendo comer as frutas enquanto faziam as ilustrações. Desse modo, lembramos que faríamos uma salada de frutas no fim da aula, 
e então eles ficaram mais sossegados. Os alunos se agruparam e desenharam os frutos e os classificaram de acordo com as partes e o tipo de fruto. E no final da atividade expuseram seus desenhos na bancada e também saborearam uma deliciosa salada de frutas.
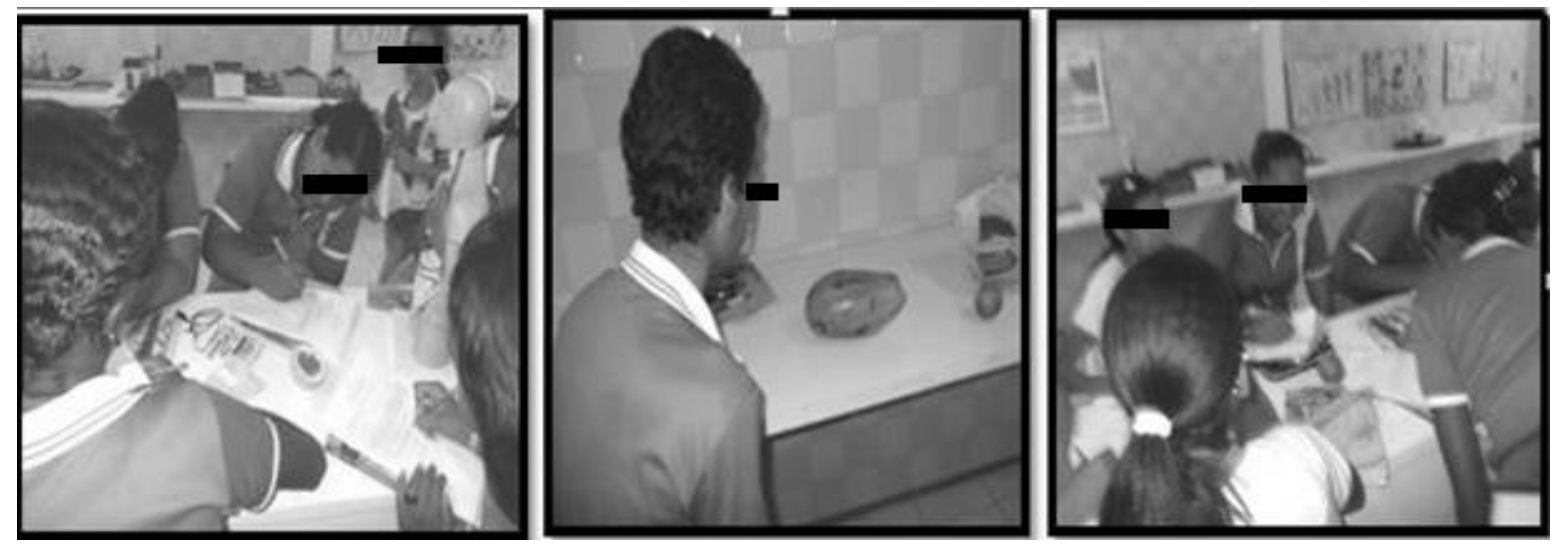

Figura 4 - Realização da segunda atividade. Autor: G.M.A.Matos

Consideramos a atividade positiva, pois os frutos trazidos foram aqueles conhecidos pelos alunos, de modo que eles puderam perceber o tipo de fruto que comem no cotidiano. Quanto ao tempo para realização da prática sugerido pelo autor do recurso, consideramos que uma aula somente não é o suficiente para a execução da atividade, de forma que precisamos produzir a salada de frutas ao passo que os alunos faziam as ilustrações. Isto é, quando os grupos terminavam de ilustrar um determinado fruto, íamos preparando a salada.

Os alunos avaliaram o recurso didático de forma positiva, a maioria ( $80 \%$ dos alunos) o classificaram como muito bom, (20\%) como bom. Diferentes aspectos foram apontados nas justificativas dos alunos nas respostas dos questionários:

a) O caráter diferente e lúdico da aula

Foi uma aula diferente (Aluno " $\mathrm{Y}$ ", 13 anos).

Porque foi muito divertido desenhar as frutas (Aluno " $\mathrm{F}$ ", 14 anos).

Porque foi mais organizado e divertida (Aluno "P", 12 anos).

Porque desenhou e depois comeu salada de fruta e foi melhor do que a primeira vez (Aluna "W", 14 anos).

Porque desenhei e foi muito diferente e etc... (Aluna " $A$ ", 13 anos).

Fizemos coisas diferentes fora da sala de aula (...). (Aluna "N", 13 anos).

Porque foi uma aula que trabalho mais com frutas desenhos e etc... (Aluna "S", 13 anos).

Porque devemos fazer mais vezes (Aluna “O”, 13 anos).

Porque foi muito divertido porque podemos observa como as frutas são (Aluna "Z", 15 anos). 
Porque foi uma aula que trabalhamos mais com frutas, desenhos e etc... (Aluna "S", 13 anos).

Foi maravilhoso porque estudamos e interagimos com as frutas (Aluna " $R$ ", 12 anos).

b) Oportunidade de aprofundar os conteúdos de botânica

Porque aprendemos com as frutas são com muito carolso e só com um carolso (Aluna "I", 15 anos).

Porque eu fiz uma coisa que eu gostei e também eu entendi mais dos frutos (Aluna "M", 13 anos).

Porque conhecemos o interior das frutas e comemos frutas, já mais organização (Aluna "C", 13 anos).

Porque trabalhamos com frutas conhecemos o tipo delas e como elas são por dentro (Aluna "K", 12 anos).

Porquê o aprendizado sobre as frutas, porquê é uma oportunidade de saber mais do fruto (...)(Aluna "V", 11 anos).

Quando questionados se possuíam alguma crítica e/ou sugestão, um aluno não respondeu, vinte um disseram que não, sendo que alguns dos alunos destacaram o quanto gostaram da aula, três alunos deram sugestões para a melhoria da atividade:

Sim que a turma colaborace e não fazer muita bagunça nem muita suada. (Aluno "I", 15 anos).

Sim. Ter mais comida. (Aluno " $\mathrm{T}$ ", 12 anos).

Sim porque deve ter mais comida. (Aluno "J", 12 anos).

A avaliação do professor foi igualmente positiva, em consonância com a realizada pelos alunos. Ele considerou muito boa a adequação da prática à série de ensino, a participação dos alunos na atividade, aos objetivos propostos assim como em relação às informações necessárias para a compreensão do tema em estudo e a contribuição da atividade para a aprendizagem dos alunos. Quanto ao tempo recomendado para a aplicação do recurso ele imprime o conceito satisfatório. Esta questão do tempo de realização da atividade foi também um cuidado tomado pelos pesquisadores, de forma que fizeram a salada de frutas ao passo que os grupos faziam suas ilustrações. A decisão pela elaboração da salada por parte dos pesquisadores também considerou o fato de que a prática continha objetos cortantes, não sendo seguro deixar os alunos manipular estes objetos.

Para os pesquisadores a segunda atividade se adequa à série proposta, com conteúdo atualizado, apresentando coerência entre as informações, contendo recursos visuais de boa qualidade, apresentando-se como uma atividade inovadora, original e criativa, de fácil execução, atingindo aos objetivos propostos. No decorrer da atividade, os alunos se organizaram e, seguindo o roteiro proposto pelo autor, trabalharam com criatividade e abstração. Durante a aula os alunos 
puderam: ver, manusear, desenhar, dialogar, criar conceitos e depois comer a salada de frutas preparada com os frutos que foram expostos na atividade de modo a tornar a aprendizagem mais significativa, importante para a compreensão do conteúdo. Se o conteúdo não for significativo para o aluno, ele será armazenado de maneira isolada, podendo ser esquecido em seguida, ocorrendo apenas a aprendizagem mecânica (MOREIRA; CABALLERO; RODRÍGUEZ, 1997)

\subsection{Terceira atividade - Jogo da memória.}

A terceira atividade prática selecionada foi um Jogo da memória retirado do trabalho de monografias de Daniel Silva Melo (2011).

De acordo com a proposta do autor, esta atividade apresenta as mesmas regras dos demais jogos da memória. O diferencial está que este jogo não traz imagens iguais para formar o par, visto que uma carta traz o hábito da planta com inflorescência e outra somente a inflorescência. Desta forma o aluno terá que prestar bastante atenção à região reprodutiva da planta na carta selecionada. Esta atividade teve que ser readequada para ser aplicada na turma do sétimo ano.

Para que o jogo fosse aplicado houve a necessidade de uma introdução sobre esta família, pois a maioria dos alunos não conheciam estas plantas, de acordo com as declarações deles quando perguntamos quais deles conheciam uma bromélia. Para tanto, adaptamos a monografia de Marize de Jesus Santiago (2007).

Este recurso foi utilizado como auxiliar na parte de introdução à morfologia e importância ecológica das bromélias, a partir da qual fora construído um banner explicativo. Ainda para complementar o conteúdo sobre a referida família, levou-se um indivíduo de uma espécie de bromélia para eles visualizarem melhor a planta. Neste caso, foi possível observar a importância de antes de se aplicar um determinado recurso didático durante as aulas práticas, o professor ter consciência que tal atividade se adequa ou não aos seus alunos, caso seja preciso poderá fazer adaptações necessárias ao nível cognitivo de seus alunos.

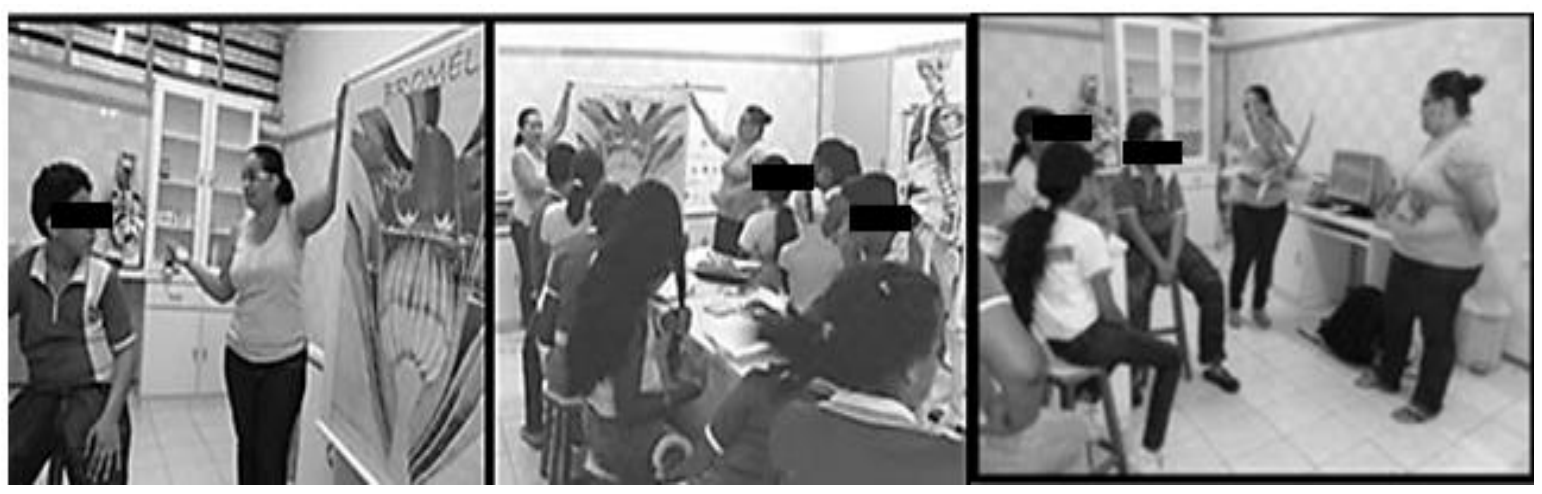

Figura 5 - Painel explicativo e espécime de bromélia utilizado na quarta atividade. Autor: G.M.A.Matos

No dia de realização desta atividade havia 24 estudantes presentes. A realização desta atividade foi a mais "tranquila" em relação à agitação e conversas entre os alunos, posto que os alunos ficaram atentos às explicações sobre a bromélia, observaram a planta e fizeram perguntas de forma interessada. Como os estudantes já conhecem as regras de jogos de memória, o momento de maior bagunça foi para dividir os grupos que iriam jogar. Eles reclamaram do grau de dificuldade e do tempo de duração, mas não perderam o foco do jogo, tentando vencer. 


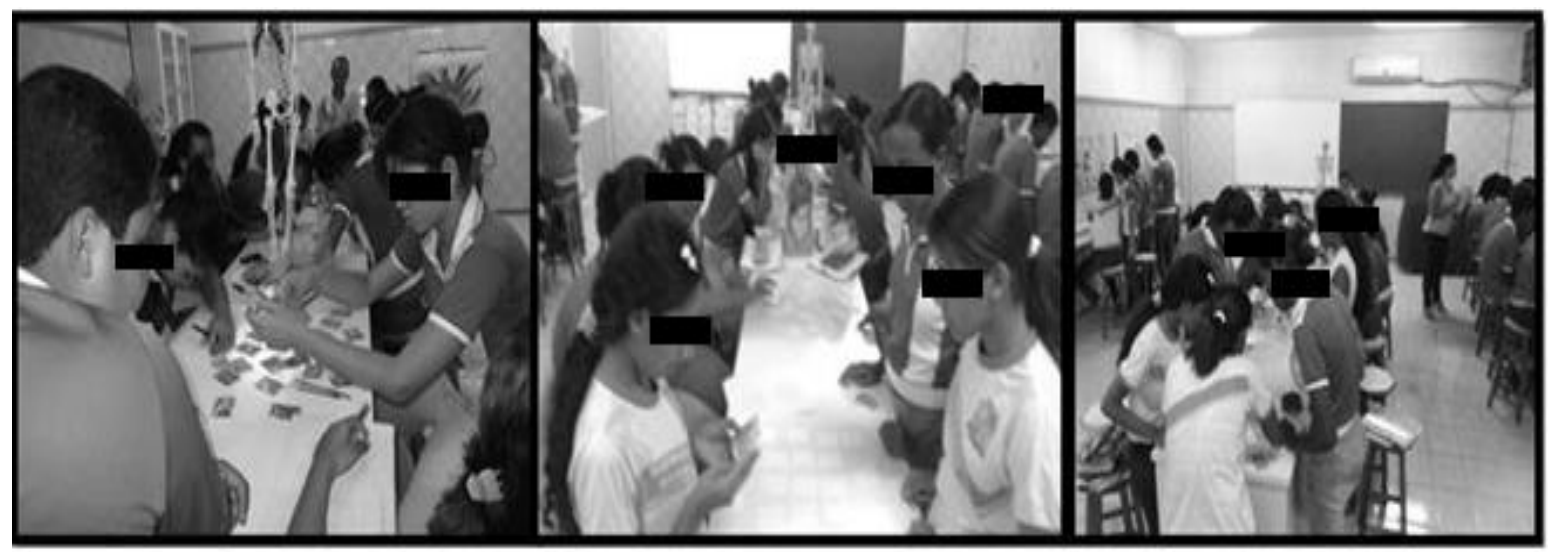

Figura 6 - Realização da segunda parte da quarta atividade (jogo da memória). Autor: G.M.A.Matos

Em relação à duração da atividade, ela é possível de ser realizada em uma aula, conforme indicação do autor do trabalho. A atividade destacou o quanto os alunos precisam ser estimulados a observar melhor as coisas ao redor, pois muitos ficaram impressionados com as bromélias que são tão comuns em jardins e parques públicos.

Os alunos avaliaram o recurso didático de forma positiva, a maioria ( $80 \%$ dos alunos) a classificaram como muito boa, (20\%) como boa. Diferentes aspectos foram apontados nas justificativas dos alunos nas respostas dos questionários:

O caráter diferente e lúdico da aula

Foi muito divertido ganhei o jogo (Aluna " $\mathrm{C}$ ", 13 anos).

Porque eu não estava na sala e foi uma aula diferente (Aluna "B", 13 anos).

Porque eu gostei do jogo (Aluna "M", 13 anos).

Porque ganhei o jogo (Alun "X", 12 anos).

Porque foi muito diferente (Aluna " $F$ ", 14 anos).

Foi divertido (Aluna "W", 14 anos).

Porque jogamo. (Aluna "S", 13 anos).

Porque um jogo que usa a memória (Aluna "Z", 15 anos).

Foi muito bom o jogo (Aluna "A", 13 anos).

Sem palavras!!! (Aluno "P", 12 anos).

Por todos os motivos (Aluna "V", 11 anos).

a) Nível de dificuldade do jogo

Porque foi satisfatória mais o jogo tava muito difícil (Aluna "O", 13 anos).

Foi difícil (Aluno " $Y$ ", 13 anos). 
Porque ele foi um jogo difícil de jogar mais não só pelas imagens mas sim pelos nomes (Aluno "I",15 anos).

b) Oportunidade de aprofundar os conteúdos de botânica

Porque eu mim diverti, ganhei o jogo e aprendi mais sobre as plantas. (Aluna "E", 12 anos).

Porque usamos a mente e aprendemos os nomes das plantas (Aluna " $\mathrm{K}$ ", 14 anos).

Quando questionados se possuíam alguma crítica e/ou sugestão, três alunos não responderam, o restante disse que não, sendo que alguns alunos destacaram o quanto gostaram da aula. No entanto uns alunos ressaltaram a questão do comportamento durante realização da atividade:

Não. Porque eu me comportei e prestei atenção na aula de hoje (Aluno "I", 15 anos).

Não. Porque foi e nós comportamos (Aluna "E", 13 anos).

A avaliação do professor não é positiva, contradizendo com a realizada pelos alunos, que mesmo achando difícil gostaram muito da atividade. Ele considerou satisfatória a adequação da prática à série de ensino, a participação dos alunos durante a atividade, os objetivos propostos pela atividade, como também a contribuição da prática para a aprendizagem dos alunos. Contudo, ele atribui o conceito bom a prática em relação às informações necessárias para a compreensão do tema em estudo e ao tempo estipulado para a elaboração da atividade. No final ele sugere que, antes da atividade, deveriam ser trabalhados com os alunos os conceitos de espécies e nomenclatura científica.

Os pesquisadores consideraram que, segundo os parâmetros analisados, o conteúdo da quarta atividade não se adequou totalmente à série, sendo necessárias algumas adaptações para ser aplicada no ensino fundamental, no entanto, poderia ser aplicado mais facilmente ao ensino médio. $O$ aspecto lúdico do jogo é importante para o ensino de botânica, pois se o conteúdo tiver alguma aplicabilidade, o professor poderá adaptá-lo a algum tipo de jogo e utilizar com um recurso de reforço ou avaliação, e desta maneira tornar a atividade mais atraente e motivadora, atingindo assim diferentes objetivos simultaneamente (LOPES, 2005).

Após as adequações, a atividade apresentou-se como um recurso inovador, com informações coerentes, boa qualidade visual, sem riscos para os alunos. Apesar dos alunos sentirem dificuldade na execução do jogo, esta atividade foi a que mais despertou interesse, participação e envolvimento dos alunos, demostrando assim a importância do caráter lúdico do jogo, na qual a brincadeira estimulou a memória e o raciocínio, contribuindo para o reforço, ilustração e construção do conhecimento do aluno de maneira interessante e prazerosa, atingindo aos objetivos propostos pela atividade. 


\section{CONSIDERAÇÕES FINAIS}

Os resultados deste trabalho mostram a importância de se propor atividades diferenciadas, visando promover um aprendizado mais dinâmico e significativo quanto aos conteúdos de Ciências, em geral, de Botânica, em particular. Durante a execução das atividades práticas de Botânica, confirmamos a importância dos recursos didáticos. No decorrer de cada prática, era perceptível o entusiasmo e interesse dos alunos, pois eles desenvolviam diferentes habilidades e davam maior significado aos conteúdos estudados.

O professor participante desta pesquisa considerou os recursos didáticos como facilitadores dos processos de ensino e aprendizagem. Entretanto, apesar de atribuir conceito satisfatório em algumas respostas aos questionários, ele só propôs sugestões de melhoria para uma dentre as três atividades desenvolvidas. A satisfação do professor encontrou ressonância nas falas dos seus alunos, também participantes desta pesquisa. Para estes, observamos que todas as práticas foram bem aceitas, expressando assim o valor que os recursos didáticos têm dentro da proposta pedagógica aplicada nas aulas de Ciências. Somando-se a essa proposta, observamos que objetivos e regras metodológicas claras levam os alunos a se organizar e construir o conhecimento de forma dinâmica, significativa e prazerosa.

Os diferentes recursos didáticos aqui testados criaram um ambiente lúdico, no qual a quebra da rotina tornou as aulas mais atraentes e melhor aproveitadas pelos alunos, facilitando a assimilação e compreensão dos conceitos botânicos propostos nas atividades. Este fato demonstra a aplicabilidade de tais recursos didáticos como suporte de introdução ou de reforço de um conteúdo durante aulas práticas de Ciências. Foi observado que as práticas tornaram as aulas mais proveitosas, facilitaram a comunicação entre os alunos e também entre o professor e os alunos, pois esta parceria e troca de conhecimento contribui para a assimilação e construção do conhecimento em Botânica.

Contudo, é importante ressaltar que a aplicação de um recurso didático não deve ser seguida como um receituário a ser aplicado em todas as turmas da mesma maneira. Conforme as experiências aqui relatadas, algumas dificuldades na execução das aulas práticas ocorrem, tais como falta de estrutura e materiais necessários à realização das práticas, como também tempo adequados para realização destas aulas. Além disso, é preciso considerar a agitação dos alunos, somado à grande quantidade de alunos por turma.

Somado a estes fatores, é fundamental ponderar a respeito da necessidade de adequação da proposta ao público que será aplicada. Desse modo, deve haver uma atenção maior por parte do professor ao considerar um recurso em sua proposta pedagógica, pois na maioria das vezes são necessárias algumas adaptações. Estas dependem de vários fatores, dentre eles o nível cognitivo da turma e o contexto sociocultural no qual eles estão inseridos.

A maioria dos recursos aqui avaliados contribuiu para uma aprendizagem prazerosa e significativa, pois o contato com os materiais expostos durante as atividades possibilitou aos alunos perceberem as plantas no cotidiano, sua importância e diversidade.

\section{REFERÊNCIAS BIBLIOGRÁFICAS}

1. ANDRADE, M.L.F.; MASSABNI, V.G. O Desenvolvimento de Atividades Práticas na Escola: Um 
desafio para os professores de ciências. Ciências \& Educação, v. 17, n. 4, p. 835-854, 2011.

2. ANDRADE, D.; LIMA, P. S.; COUTO,N. C.; RIBEIRO, T. N. A Produção do Conhecimento e a (Re)Construção da Prática Pedagógica na Busca da Contextualização do Ensino de Química. In: ARAUJO, M. I. O.; SOARES, M. J. N.; ANDRADE, D. (org.). Desafios da Formação de Professores Para o Século XXI: A construção do novo olhar sobre a prática docente. São Cristóvão: Editora UFS, 2009.

3. BARRATT, N. M. Field Botanist for a Day: A Group Exercise for the Introductory Botany Lab. The American Biology Teacher, V.66, n. 5, p. 361 - 362, maio, 2004.

4. BATISTA, A. A. G. A avaliação dos livros didáticos: para entender o programa nacional do livro didático (PNDL). In: ROJO, R. H. \& BATISTA, A. A. G. (Org.). Livro didático de língua portuguesa, letramento e cultura da escrita. Campinas: Mercado de Letras, 2003.

5. BIZZO, N. Ciências: fácil ou difícil? 1a ed. São Paulo: Biruta, 2009.

6. BRASIL. Secretaria de Educação Fundamental. Parâmetros curriculares nacionais: introdução aos parâmetros curriculares nacionais / Secretaria de Educação Fundamental. - Brasília : MEC/SEF, 1997.

7. BRASIL. Secretaria de Educação Fundamental. Parâmetros curriculares nacionais: terceiro e quarto ciclos: apresentação dos temas transversais / Secretaria de Educação Fundamental. Brasília: MEC/SEF, 1998.

8. CAVASSAN, O; SENICIATO, T. O ensino de botânica em ambientes naturais e a formação de valores estéticos. IN:CONGRESSO NACIONAL DE BOTANICA, 58, 2007, São Paulo. Anais...São Paulo, 2007. p. 673 - 677. CD-ROM.

9. DELIZOICOV, D.; ANGOTTI, J.A.; PERNAMBUCO, M.M. Ensino de Ciências: fundamentos e métodos. São Paulo: Cortez. 364 p. 2002.

10. FIGUEIREDO, J. A. O ensino de botânica em uma abordagem ciência, tecnologia e sociedade: propostas de atividades didáticas para o estudo das flores nos cursos de ciências biológicas. Dissertação de mestrado em Ensino de Ciências e Matemática - Pontifícia Universidade Católica de Minas Gerais, Belo Horizonte, 2009.

11. FREITAS, R. de L., FURLAN, A. L. D., KUNZE, J. C., MACIEL, M. M., SANTOS, A. C. Q. dos, COSTA, R. R. da. Uso de Jogos Como Ferramenta Didática no Ensino de Botânica. In: CONGRESSO NACIONAL DE EDUCAÇÃO, 10, 2011, Curitiba. Anais... Curitiba, 2011.

12. FLICK, U. Introdução à pesquisa qualitativa. Porto Alegre: Artmed. 405 p. 2009.

13. KRASILCHIK, M. Prática de Ensino de Biologia. São Paulo: EDUSP. 2004.

14. LIBÂNEO, J. C. Didática e trabalho docente: Mediação Didática do Professor nas Aulas. In: LIBÂNEO, J. Didática: Velhos e Novos Temas. Disponível em: http://professor.ucg.br/ SiteDocente/admin/arquivosUpload/5146/material/Did\%C3\%A1tica\%20-

\%20\%20Velhos\%20e\%20novos\%20temas.doc. Último acesso em: 20 abr. 2013.

15. LOPES, M. G. Jogos na Educação: Criar, fazer, Jogar. 6 ed. - São Paulo, Cortez, 2005.

16. MARCONI, M. A.; LAKATOS, E. M.. Técnicas de pesquisa: planejamento e execução de pesquisas, amostragens e técnicas de pesquisa, elaboração, análise e interpretação de dados. São Paulo: Atlas, 2010.

17. MOREIRA, M, A; CABAllero, M. C.; ROdRíGueZ, M. L. Aprendizagem Significativa: Um 
Conceito Subjacente. In: ENCUENTRO INTERNACIONAL SOBRE EL APRENDIZAJE SIGNIFICATIVO, 1997, Burgos. Anais... Burgos, 1997. pp. 19 - 44.

18. NETA, M. A. F.; PAES, L. S.; ALENCAR, B. C. M.; LUCENA, J. M. Estratégia Didática Para o Ensino de Botânica Utilizando Plantas da Medicina Popular. CONGRESSO NORTE-NORDESTE DE PESQUISA E INOVAÇÃO, 5, 2010, Maceió. Anais...Maceió, 2010.

19. NETO, J. M.; FRACALANZA, H. O Livro Didático de Ciências: Problemas e Soluções. Ciência \& Educação, v. 9, n. 2, p. 147-157, 2003.

20. OLIVEIRA, R. C. Iniciativas Para o Aprimoramento do Ensino de Botânica. In: BARBOSA, L. M.; SANTOS-JUNIOR, N. A. dos. (Org.). A Botânica no Brasil: Pesquisa, Ensino e Politicas Ambientais. São Paulo: Sociedade Botânica do Brasil, 2007.

21. SANTOS, D. Y. A. C. ; CHOW, F. ; FURLAN, C. M. Os professores do ensino básico e o ensino de Botânica. IN:CONGRESSO NACIONAL DE BOTANICA, 59, 2008, Natal. Anais...Natal, 2008. p. 673 - 677. CD-ROM.

22. SILVA, F.S.S.; MORAIS, L.J.O.; CUNHA, I.P.R. Dificuldades dos professores de biologia em ministrar aulas práticas em escolas públicas e particulares do município de Imperatriz (MA) . Revista Uni, v.1, n.1, p. 135-149. 2011.

23. SILVA, S.N.; SOUZA, M.L. \& DUARTE, A.C.S. O professor de ciências e sua relação com o livro didático. IN: TEIXEIRA, P.M.M. \& RAZERA, J.C.C. [orgs.]. Ensino de Ciências: pesquisas e pontos em discussão. Capinas: Komedi, 2009. P. 147-166.

24. VASCONCELOS, S.D.; SOUTO, E. Livro Didático de Ciências no Ensino Fundamental - Proposta de Critérios Para Análise do Conteúdo Zoológico. Ciências \& Educação, v. 9,n.1, p.93 - 104, 2003.

25. ZABALA, A. A Prática Educativa: Como Ensinar, Tradução ROSA, E. F. da F.; Porto Alegre: Artmed, 1998.

26. WANDERSEE, J.H.; SCHUSSLER, E. Toward a theory of plant blindness. Plant Science Bulletin, Columbus, v. 47, n. 1, p. 2-9, 2001. 